\title{
RESEARCH
}

Open Access

\section{The impact of a multi-domain intervention on cerebral glucose metabolism: analysis from the randomized ancillary FDG PET MAPT trial}

Julien Delrieu ${ }^{1,2,3^{*}+} \mathbb{D}$, Thierry Voisin ${ }^{2,3 \dagger}$, Laure Saint-Aubert ${ }^{4}$, Isabelle Carrie ${ }^{3}$, Christelle Cantet ${ }^{2,3}$, Bruno Vellas ${ }^{2,3}$, Pierre Payoux ${ }^{5,6}$ and Sandrine Andrieu ${ }^{2,7}$

\begin{abstract}
Background: The Multidomain Alzheimer Preventive Trial (MAPT) was designed to assess the efficacy of omega-3 fatty acid supplementation, multidomain intervention (MI), or a combination of both on cognition. Although the MAPT study was negative, an effect of Ml in maintaining cognitive functions compared to placebo group was showed in positive amyloid subjects. A FDG PET study (MAPT-NI) was implemented to test the impact of MI on brain glucose metabolism.
\end{abstract}

Methods: MAPT-NI was a randomized, controlled parallel-group single-center study, exploring the effect of MI on brain glucose metabolism. Participants were non-demented and had memory complaints, limitation in one instrumental activity of daily living, or slow gait. Participants were randomly assigned (1:1) to "Ml group" or "No Ml group." The Ml consisted of group sessions focusing on 3 domains: cognitive stimulation, physical activity, nutrition, and a preventive consultation. $\left[{ }^{18} \mathrm{~F}\right] \mathrm{FDG}$ PET scans were performed at baseline, 6 months, and 12 months, and cerebral magnetic resonance imaging scans at baseline. The primary objective was to evaluate the MI effect on brain glucose metabolism assessed by $\left[{ }^{18} \mathrm{~F}\right] \mathrm{FDG}$ PET imaging at 6 months. The primary outcome was the quantification of regional metabolism rate for glucose in cerebral regions involved early in Alzheimer disease by relative semi-quantitative SUVr (FDG-based AD biomarker). An exploratory voxel-wise analysis was performed to assess the effect of $\mathrm{Ml}$ on brain glucose metabolism without anatomical hypothesis.

Results: The intention-to-treat population included 67 subjects (34 in the Ml group and 33 in the No Ml group. No significant $\mathrm{Ml}$ effect was observed on primary outcome at 6 months. In the exploratory voxel-wise analysis, we observed a difference in favor of Ml group on the change of cerebral glucose metabolism in limbic lobe (right hippocampus, right posterior cingulate, left posterior parahippocampal gyrus) at 6 months.

(Continued on next page)

\footnotetext{
*Correspondence: delrieu.@@chu-toulouse.fr

${ }^{\dagger} J u$ lien Delrieu and Thierry Voisin contributed equally to this work.

'Pôle gériatrie, Cité de la santé, Place Lange - TSA 60033, 31059 Toulouse Cedex 9, France

${ }^{2}$ INSERM UMR 1027, Toulouse, France; University of Toulouse III, Toulouse, France

Full list of author information is available at the end of the article
}

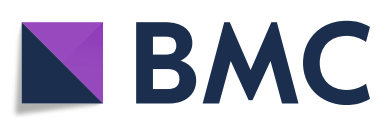

(c) The Author(s). 2020 Open Access This article is licensed under a Creative Commons Attribution 4.0 International License, which permits use, sharing, adaptation, distribution and reproduction in any medium or format, as long as you give appropriate credit to the original author(s) and the source, provide a link to the Creative Commons licence, and indicate if changes were made. The images or other third party material in this article are included in the article's Creative Commons licence, unless indicated otherwise in a credit line to the material. If material is not included in the article's Creative Commons licence and your intended use is not permitted by statutory regulation or exceeds the permitted use, you will need to obtain permission directly from the copyright holder. To view a copy of this licence, visit http://creativecommons.org/licenses/by/4.0/ The Creative Commons Public Domain Dedication waiver (http://creativecommons.org/publicdomain/zero/1.0/) applies to the data made available in this article, unless otherwise stated in a credit line to the data. 
(Continued from previous page)

Conclusions: MI failed to show an effect on metabolism in FDG-based AD biomarker, but exploratory analysis suggested positive effect on limbic system metabolism. This finding could suggest a delay effect of MI on AD progression.

Trial registration: ClinicalTrials.gov Identifier, NCT01513252.

Keywords: Clinical trials randomized controlled, All cognitive disorders/dementia, Alzheimer's disease, PET, Prevention

\section{Background}

The MAPT (Multidomain Alzheimer Prevention Trial) study has tested the effect of omega 3 polyunsaturated fatty acid supplementation (omega-3) and multidomain intervention (MI), alone or in combination, on cognitive decline in elderly people with memory complaint [1]. The MI and omega-3, alone or in combination, had no significant effect on cognitive decline over 3 years [2]. However, the ancillary amyloid MAPT study (MAPTAV45) has provided new insights on the effects of MI alone or in combination with omega-3 in positive amyloid subjects in maintaining cognitive functions compared to the placebo group [3]. Thus, a MI effect can be suspected at early stages of $\mathrm{AD}$.

The implementation of $\mathrm{AD}$ biomarkers in prevention trials has become increasingly important to explore MI effect on cognition in a specific sub-population [3], and as outcome to better understand its mechanism of action [4]. To investigate the presumed effect of MI in early $\mathrm{AD}$, we designed the MAPT-NeuroImaging (MAPT-NI) study, a randomized controlled parallelgroup monocentric study, exploring the MI effect on glucose metabolism, in particular in cerebral areas involved early in neural dysfunction of AD. Metabolism by positron emission tomography with fluorine-18 fluorodeoxyglucose $\left(\left[{ }^{18} \mathrm{~F}\right] \mathrm{FDG}\right.$ PET $)$ is considered as an $\mathrm{AD}$ biomarker [5] and a potential surrogate marker of $\mathrm{AD}$ progression [6]. Indeed, cerebral metabolism is proposed as biomarker of "neuronal injury" in the revised criteria proposed by the national institute of aging and Alzheimer association (NIA-AA) and as biomarker of "progression" in the research criteria proposed by the international working group-2 [7, 8]. Progressive decrease of metabolism in associative cortices is closely related to progressive cognitive impairment and allows monitoring of disease progression not provided by pathophysiological biomarkers [9]. Brain metabolism measurements may be used in clinical trials as endpoint to better understand the mechanisms of action of an intervention $[6,10,11]$. The number of published trials using $\left[{ }^{18}\right.$ F]FDG PET as outcome is limited, and in large MI trials (Prevention of Dementia by Intensive Vascular Care, Finnish Geriatric Intervention Study to Prevent
Cognitive Impairment and Disability, FINGER) [12, 13], glucose metabolism has never been-to date-used for this purpose. The MAPT-NI study is a unique opportunity to assess the impact of a MI, alone or in combination with omega-3, on metabolism and to explore their potential mechanism of action on cognitive performance. We hypothesize that the MI, in non-demented subjects, alone or in combination with omega-3, positively affects metabolism in regions early involved in $\mathrm{AD}$ after 6month intervention.

\section{Methods}

\section{Study design and participants}

All subjects enrolled in this ancillary $\left[{ }^{18}\right.$ F]FDG PET study were participants from the MAPT study. The MAPT protocol is registered on a public-access clinical trial database (www.clinicaltrials.gov, no. NCT01513252). MAPTNI study protocol was approved by the French Ethics Committee in Toulouse and AFSSAPS (national agency for the safety of drugs and health products) in February 2009. One hundred seventy-eight subjects were asked consecutively to participate to MAPT-NI at their inclusion visit in MAPT, and 68 subjects have been included. Written informed consent was given by all participants. Included subjects were 70 years old and over and fulfilled at least one of the following three clinical criteria: spontaneous memory complaint, limitation in one instrumental activity of daily living, or slow gait. Subjects with dementia were not included in this trial.

$\left[{ }^{18}\right.$ F]FDG PET scans were performed at baseline (within 1 month following written consent), 6 months, and 12 months, and cerebral magnetic resonance imaging (MRI) scans at baseline. Baseline MRI scans were designed to detect significant exclusion abnormalities (surgical lesions and significant cerebrovascular lesions) and to assess medial temporal lobe atrophy using a $0-4$ rating scale [14]. APOE genotyping was determined from blood samples collected and stored at baseline for RNA/DNA extraction.

\section{Randomization and masking}

In MAPT trial, participants were randomly assigned (1:1: 1:1) to one of the four following groups: "MI plus 
omega-3", "MI only", "Omega-3 only", and "Placebo only". At the same time in MAPT-NI ancillary study, participants were randomly assigned (1:1) to MI group or No MI group. However, MAP-NI participants of MI group and No MI group were also allocated to omega-3 or placebo. At the end of the MAPT trial, the distribution of the subjects between the 4 interventional groups was only known after unblinding. All participants, neuropsychologists, and research staff were blinded to omega-3 or placebo assignment and to $\left[{ }^{18}\right.$ F]FDG PET assessment.

\section{Procedures}

\section{Multi-domain intervention and omega-3 supplementation}

The MI consisted of group sessions focusing on 3 domains: cognitive stimulation, physical activity, nutrition, and a preventive consultation as described previously [1, 2]. Briefly, each session included $60 \mathrm{~min}$ of cognitive training, $45 \mathrm{~min}$ of demonstrations about physical activity, and $15 \mathrm{~min}$ of nutritional advice. Participants with MI underwent 12 sessions of $2 \mathrm{~h}$ in the first 2 months, followed by a $1-\mathrm{h}$ session once a month, and finally a 2 -h session at 12 months. The active supplement used was V0137, an oil mixture containing natural fish oil with a minimum of $65 \%$ docosahexaenoic acid (DHA) and a maximum of $15 \%$ eicosapentaenoic acid (EPA). Participants took two capsules daily of either the supplement or the placebo.

\section{Cognitive assessment}

Clinical visits were scheduled at baseline, 6 months, and 12 months to assess physical and cognitive performances and adherence. A comprehensive assessment of cognitive functions was performed, including the Free and Cued Selective Reminding Test (FCRST) [15], the Controlled Oral Word Association Test and Category Naming Test (COWAT and CNT) [16], the Digit Symbol Substitution Subtest of the Wechsler Adult Intelligence Scale-Revised [17], the Trail-Making Test (TMT) [18], the Mini-Mental State Examination (MMSE) [19], and the Clinical Dementia Rating (CDR) [20]. A cognitive composite score was calculated at each time point (baseline, 6 months, 12 months) by averaging the standardized $Z$ scores at four cognitive tests (FCRST, CNT, Digit Symbol Substitution test, orientation items of MMSE) [21].

\section{$\left[{ }^{18}\right.$ F]FDG PET and MRI exams}

$\left[{ }^{18} \mathrm{~F}\right]$ FDG PET scans were acquired at the Toulouse Hospital PET center, on a Biograph ${ }^{\text {TM }} 6$ TruePoint $^{\text {Tw }}$ (Siemens Medical Solutions, Knoxville, TN USA) high-resolution $\mathrm{PET} / \mathrm{CT}$ scanner (3D detection mode, producing images with $1 \times 1 \times 1.5-\mathrm{mm}$ voxels and a spatial resolution of 5 $\mathrm{mm}$ full width at half maximum at the field of view center), during $20 \mathrm{~min}$ in list mode, $30 \mathrm{~min}$ after injection of $1.85 \mathrm{MBq} / \mathrm{kg}$ weight of $\left[{ }^{18} \mathrm{~F}\right] \mathrm{FDG}$ on average $( \pm 10 \%)$. All images benefited from a partial volume effect correction on this machine. Plasma glucose levels of all MAPT-NI participants have been checked before FDG PET scans with a fast of at least $4 \mathrm{~h}$ (glucose threshold $<10 \mathrm{mmol} / \mathrm{l})$. For each patient, $\left[{ }^{18} \mathrm{~F}\right]$ FDG PET scans from all time points were first realigned onto their mean image and normalized using the same transformation matrix in the MNI space using a PET template in Statistical Parametric Mapping 12 (SPM12) software running on Matlab. Cortical standardized uptake value ratio (SUVr) images were obtained using the gray matter of the cerebellum as reference region. Regions of interest (ROIs) involved early in AD were selected based on the MetaROI approach described by Landau et al. [22]. $\left[{ }^{18}\right.$ F]FDG mean SUVr uptake was quantified in 6 predefined cortical ROIs, extracted from a cortical atlas derived from the Harvard-Oxford atlas (FSL software, The University of Oxford): right and left posterior cingulate, angular gyrus, and middle/inferior temporal areas.

The MRI scans were performed at baseline visit using a standardized protocol including these sequences: 3D T1-weighted, T2 FLAIR, T2 TSE, and T2 GRE. A local independent radiologist assessed MRI scans to detect significant exclusion abnormalities.

\section{Adherence}

For supplementation, adherence was assessed by counting the number of capsules returned by participants. For the MI, adherence was calculated as the percentage of intervention sessions attended. Participants were deemed adherent if they took at least than $75 \%$ of the prescribed capsules and attended at least $75 \%$ of the MI group sessions (if applicable).

\section{Objectives and outcomes \\ Primary objective}

The primary objective was to evaluate the MI effect on brain glucose metabolism assessed by $\left[{ }^{18} \mathrm{~F}\right] \mathrm{FDG}$ PET imaging at 6 months. The primary outcome was the quantification of regional metabolism rate for glucose by relative semi-quantitative SUVr. This global SUVr value (AD-based SUVr) was used as an FDG-based AD biomarker and primary outcome (supplementary Fig. 1).

\section{Secondary and exploratory objectives}

The secondary objectives were (1) to assess the longterm effect of MI on AD-based SUVr at 12 months and (2) to test the effect of omega-3 supplementation on AD-based SUVr at 6 and 12 months.

The exploratory objectives were (1) to assess the effect of combination of $\mathrm{MI}$ and omega-3 supplementation on AD-based SUVr; (2) to explore, using a voxel-wise 
approach, the effect of interventions on metabolism; (3) to test the effect of MI and omega-3 supplementation according adherence; and (4) to explore effect of interventions on cognitive composite score.

\section{Sample size}

The number of participants required was calculated referring to study of De Leon et al. [23]. We expected a $5 \%$ increase on cerebral glucose metabolism in the MI group and no progression in the No MI group. For a power of $90 \%$ for bilateral alpha risks of 0.05 (in the case of 10 comparisons performed), the sample size to be recruited was 34 subjects per group or 68 subjects for the entire study $(n=1680)$.

\section{Statistical analysis}

\section{Baseline demographic analysis}

We compared baseline characteristics of subjects according to their group intervention: (1) "MI group" vs. "No MI group", (2) "Omega-3 group" vs "No omega-3 group", and (3) "MI only group" vs "Omega-3 only group" vs "MI plus omega-3 group" vs "Control group". We used $\chi^{2}$ or Fisher's exact (for expected values <.05) tests for categorical variables, one-way analyses of variance for quantitative variables with normal distributions (Student's tests or Fisher's tests), and non-parametric tests (Kruskal-Wallis test) for quantitative variables without normal distributions.

\section{ROI-based approach}

Analysis was conducted in the intention-to-treat (ITT, $n=67$, primary analysis) population and a sub-sample with adherence (exploratory analysis). ITT population included all randomly assigned participants who completed at least one $\left[{ }^{18} \mathrm{~F}\right] \mathrm{FDG}$ PET scan at baseline, 6 months, or 12 months. In the sub-sample with adherence analysis, participants were deemed adherent if they attended at least $75 \%$ of MI group sessions $(n=20)$ and took at least $75 \%$ of the prescribed capsules $(n=30)$.

Linear mixed-model repeated-measures analyses were applied to baseline, 6-month, and 12-month data to assess between-group differences in the change on $\mathrm{AD}$ based SUVr along time. Time was used as a continuous variable. All the models were completed with and without adjustments for gender, age, level of education, global CDR score, APOE-4 genotype, and group intervention. For each linear mixed model, we included subject-specific random effects to take into account the intra-subject correlation: a random intercept to take into account the heterogeneity of the AD-based SUVr at baseline and a random slope to take into account the heterogeneity of the slopes between subjects if this parameter was significant. In the unadjusted linear mixed models, we included the following fixed effects: intervention group, time, and interaction between group and time. All confidence intervals (CIs) were two-sided with a 95\% confidence level, and the statistical significance was set at a $p$ value $<.05$. All statistical analyses were performed using SAS software version 9.4 (SAS Institute Inc., Cary, NC).

\section{Voxel-wise approach}

To investigate potential group differences on metabolic changes without anatomical a priori, we performed voxel-wise analyses on smoothed $(8 \times 8 \times 8)\left[{ }^{18} \mathrm{~F}\right] \mathrm{FDG}$ SUVr images using SPM12. To address the effect of MI and omega- 3 along time, voxel-wise $t$ tests were performed to assess change on glucose metabolism from baseline to 6 months and 12 months with groups defined as MI group vs No MI group and Omega-3 vs No omega-3. $\left[{ }^{18} \mathrm{~F}\right] \mathrm{FDG}$ SUVr images were smoothed $(8 \times$ $8 \times 8)$ and delta images ( 6 months-baseline, 12 months- 6 months, and 12 months-baseline) were created for each subject. Voxel-wise differences on changes in glucose metabolism from baseline to 6 and 12 months between the 4 randomized groups were assessed using a one-way ANOVA. A peak threshold of $p=.001$ (uncorrected, and also Family Wise Error Rate <.05) with an extent threshold of $k=50$ voxels for significant clusters was chosen. The MNI coordinates of the local maxima in each significant cluster were then reported onto the HarvardOxford atlas (FSL software, The University of Oxford) for regional labeling.

\section{Results}

\section{Enrollment and rates of study completion}

Of the 345 participants from MAPT recruited at Toulouse center, 68 subjects were included in MAPT-NI. Sixty-seven FDG PET scans were performed in the MAPT-NI study at baseline, 58 and 57 respectively at 6and 12-month visits. Subjects were enrolled between May 6, 2009, and February 9, 2011. At baseline, spontaneous memory complaint was present in $57(85.07 \%)$ of the 67 participants and slow walking speed in $1(1.49 \%)$. No participants were included only on limitation in one instrumental activity of daily living. Seven (10.46\%) participants reported two of these factors, and 2 (2.99\%) reported all three factors. The flow chart of MAPT-NI participants is showed in Fig. 1. The ITT population included 67 subjects ( 34 in the MI group and 33 in the No MI group). Twenty-six (76.47\%) subjects of the MI group completed the follow-up and 31 (93.94\%) of the No MI group.

\section{Baseline characteristics}

Subjects who participated to MAPT-NI were significantly older $(76.37 \pm 4.23$ vs $75.29 \pm 4.43$ years, $p=.022)$ and had a lower Geriatric Depression Scale (GDS) score 


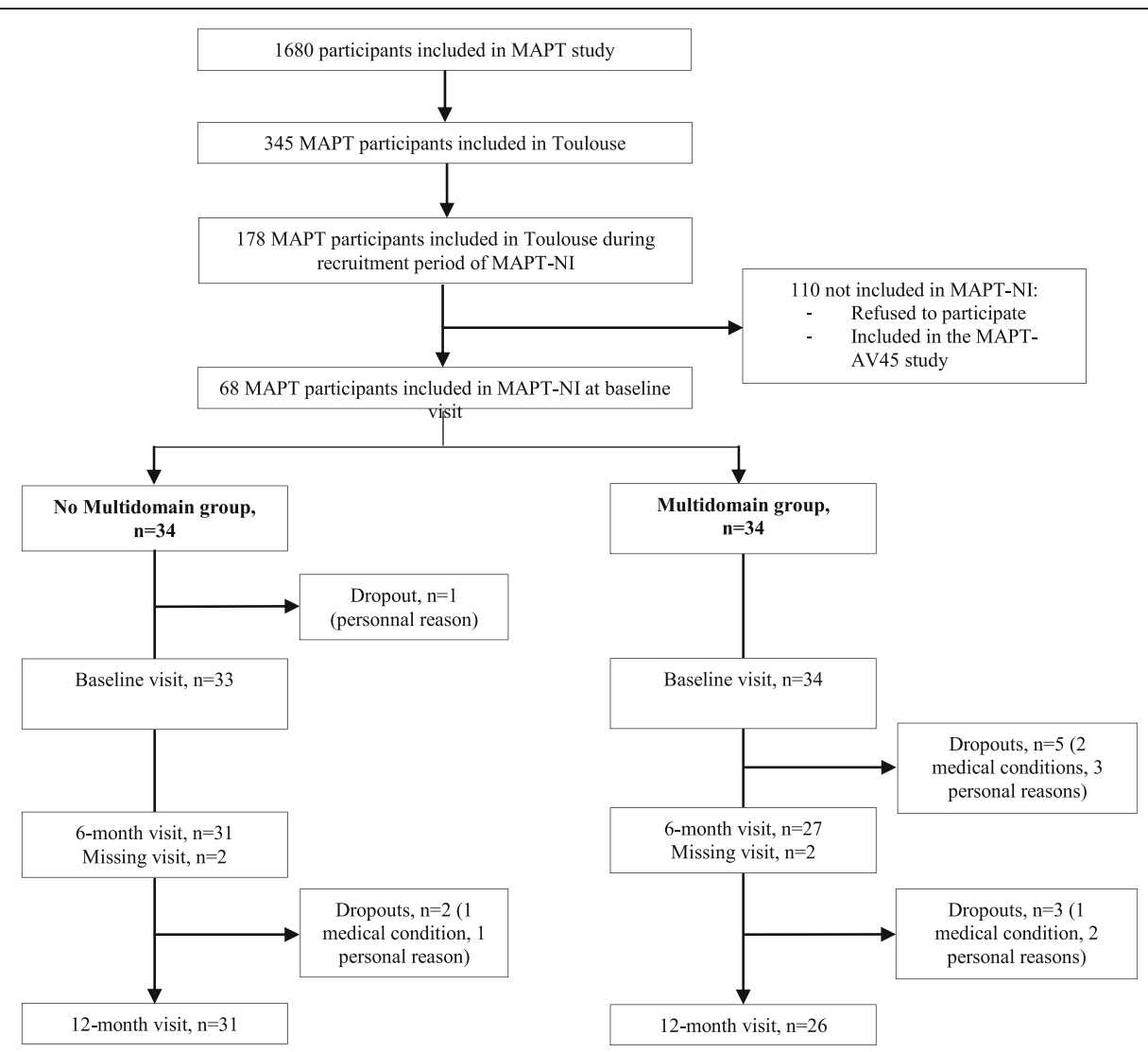

Fig. 1 Trial profile of the MAPT-NI study. Abbreviations: MAPT, Multidomain Prevention Alzheimer Trial; MAPT-NI, MAPT-Neurolmaging; PET, positron emission tomography; Ml, multidomain intervention

$(2.33 \pm 1.85$ vs $3.31 \pm 2.65, p=.005)$ than MAPT subjects non-included in MAPT-NI sub-study. Baseline characteristics of the 67 participants included in the ITT analysis are presented in the Table 1 . The MI group and No MI group did not differ significantly for baseline characteristics. The Omega-3 group and No omega-3 group differed significantly for age $(p=0.035$, Table 1$)$. Groups did not differ for diabetes and blood glucose level before FDG PET scan at baseline visit.

\section{Primary objective: impact of MI on brain glucose} metabolism at 6 months assessed by ROI-based approach Metabolism did not increase significantly in the MI group (AD-based SUVr +0.008, $p=.395$ ) and No MI group (+0.004, $p=.653$, Fig. 2) from baseline to 6 month visit. The comparison of change between the MI group and the No MI group showed a non-significant difference in favor of the MI group $(+0.004, p=.752$, Table 2).

\section{Secondary objectives}

There was no significant increase of metabolism from baseline to 12 months in the MI group $(+0.016, p=.395)$ and No MI group $(+0.008, p=.653)$. No significant difference between the MI group and No MI group was observed on AD-based SUVr change from baseline to 12 months (0.008, $p=.752$, Table 2 and Fig. 2).

Metabolism increased not significantly in the Omega-3 group and No omega-3 group from baseline to 6- (respectively +0.009 and $+0.002, p=.319$ and $p=.835)$ and 12month visits $(+0.018$ and $+0.004, p=.319$ and $p=.835)$. No omega-3 supplementation effect was observed on $\mathrm{AD}$ based SUVr change either at 6 months $(+0.007, p=.612)$ or 12 months $(+0.013, p=.612$, Table 2 and Fig. 2$)$.

\section{Exploratory objectives \\ Exploratory objectives assessed by ROI-based approach}

From baseline to 6 and 12 months, metabolism did not increase significantly in the MI plus omega-3 group (respectively +0.008 and $+0.017, p=.516)$, in the Omega- 3 only group $(+0.009$ and $+0.019, p=.445)$, and MI only group (+0.008 and $+0.017, p=.580$, Table 2 and Fig. 2$)$. The control group was the only group with a decrease of metabolism at 6- and 12-month visits (-0.002 and 0.004 ) in AD-related brain areas (Table 2), but these differences were not significant $(p=.871)$. No significant effect was found at 6 and 12 months when exploring for possible differences in metabolic change in the MI only 
Table 1 Baseline characteristics of MAPT-NI groups

\begin{tabular}{|c|c|c|c|c|c|c|c|c|c|}
\hline & \multicolumn{9}{|c|}{ TEP-FDG $(n=67)$} \\
\hline & \multirow[b]{2}{*}{$\begin{array}{l}\text { Overall } \\
\text { population } \\
(n=67)\end{array}$} & \multicolumn{2}{|l|}{$\begin{array}{l}\text { Primary } \\
\text { population }\end{array}$} & \multicolumn{6}{|c|}{ Secondary and exploratory populations } \\
\hline & & $\begin{array}{l}\text { No Ml } \\
(n=33)\end{array}$ & $\begin{array}{l}\text { MI } \\
(n=34)\end{array}$ & $\begin{array}{l}\text { No omega-3 } \\
(n=29)\end{array}$ & $\begin{array}{l}\text { Omega-3 } \\
(n=38)\end{array}$ & $\begin{array}{l}\text { Omega-3 } \\
+M I(n=20)\end{array}$ & $\begin{array}{l}\text { Omega-3 } \\
\text { only }(n=18)\end{array}$ & $\begin{array}{l}\text { MI only } \\
(n=14)\end{array}$ & $\begin{array}{l}\text { Placebo } \\
(n=15)\end{array}$ \\
\hline Male gender, $N(\%)$ & $18(26.87)$ & $8(24.24)$ & $10(29.41)$ & $8(27.59)$ & $10(26.32)$ & $7(35.00)$ & $3(16.67)$ & $3(21.43)$ & $5(33.33)$ \\
\hline Age in years, mean (SD) & $76.37(4.23)$ & $76.79(4.24)$ & $75.97(4.24)$ & $75.41(4.37)$ & $77.11(4.02)$ & $77.10(4.15)$ & $77.11(3.98)$ & $74.36(3.95)$ & $76.40(4.64)$ \\
\hline BMI (kg/m2), mean (SD) & $26.40(3.51)$ & $26.60(3.97)$ & $26.21(3.06)$ & $26.35(2.99)$ & $26.44(3.91)$ & $26.34(3.73)$ & $26.56(4.20)$ & $26.04(1.84)$ & $26.65(3.82)$ \\
\hline \multicolumn{10}{|l|}{ Education, $N(\%)$} \\
\hline $\begin{array}{l}\text { No diploma or primary } \\
\text { school certificate }\end{array}$ & $18(27.27)$ & $9(27.27)$ & $9(27.27)$ & $6(21.43)$ & $12(31.58)$ & $7(35.00)$ & $5(27.78)$ & $2(15.38)$ & $4(26.67)$ \\
\hline Secondary education & $21(31.82)$ & $11(33.33)$ & $10(30.30)$ & $7(25.00)$ & $14(36.84)$ & $6(30.00)$ & $8(44.44)$ & $4(30.77)$ & $3(20.00)$ \\
\hline High-school diploma & $9(13.64)$ & $4(12.12)$ & $5(15.15)$ & $6(21.43)$ & $3(7.89)$ & $2(10.00)$ & $1(5.56)$ & $3(23.08)$ & $3(20.00)$ \\
\hline University level & $18(27.27)$ & $9(27.27)$ & $9(27.27)$ & $9(32.14)$ & $9(23.68)$ & $5(25.00)$ & $4(22.22)$ & $4(30.77)$ & $5(33.33)$ \\
\hline APOE4 carrier, $N(\%)$ & $8(13.79)$ & $4(13.33)$ & $4(14.29)$ & $5(20.00)$ & $3(9.09)$ & $2(12.50)$ & $1(5.88)$ & $2(16.67)$ & $3(23.08)$ \\
\hline $\begin{array}{l}\text { Composite cognitive score, } \\
\text { mean (SD) }\end{array}$ & $0.05(0.69)$ & $-0.02(0.71)$ & $0.11(0.68)$ & $0.08(0.58)$ & $0.02(0.77)$ & $0.02(0.80)$ & $0.03(0.77)$ & $0.24(0.46)$ & $-0.07(0.66)$ \\
\hline $\begin{array}{l}\text { MMSE total score/30, mean } \\
\text { (SD) }\end{array}$ & $28.19(1.62)$ & $28.21(1.71)$ & $28.18(1.55)$ & $28.45(1.40)$ & $28.00(1.76)$ & $28.20(1.54)$ & $27.78(1.99)$ & $28.14(1.61)$ & $28.73(1.16)$ \\
\hline $\begin{array}{l}\text { MMSE orientation score/ } \\
10, \text { mean (SD) }\end{array}$ & $9.84(0.41)$ & $9.82(0.39)$ & $9.85(0.44)$ & $9.83(0.38)$ & $9.84(0.44)$ & $9.85(0.49)$ & $9.83(0.38)$ & $9.86(0.36)$ & $9.80(0.41)$ \\
\hline \multicolumn{10}{|l|}{ CDR score, $N(\%)$} \\
\hline $\mathrm{CDR}=0$ & $27(40.30)$ & $14(42.42)$ & $13(38.24)$ & $12(41.38)$ & $15(39.47)$ & $8(40.00)$ & $7(38.89)$ & $5(35.71)$ & $7(46.67)$ \\
\hline $\mathrm{CDR}=0.5$ & $40(59.70)$ & $19(57.58)$ & $21(61.76)$ & $17(58.62)$ & $23(60.53)$ & $12(60.00)$ & $11(61.11)$ & $9(64.29)$ & $8(53.33)$ \\
\hline \multicolumn{10}{|l|}{ FCSRT scores, mean (SD) } \\
\hline Free recall/48 & $28.30(6.81)$ & $27.67(7.47)$ & $28.91(6.16)$ & $28.79(6.22)$ & $27.92(7.29)$ & $27.90(6.54)$ & $27.94(8.25)$ & $30.36(5.47)$ & $27.33(6.69)$ \\
\hline Total recall/48 & $45.34(3.45)$ & $45.03(3.23)$ & $45.65(3.68)$ & $45.38(3.00)$ & $45.32(3.79)$ & $45.15(4.25)$ & $45.50(3.33)$ & $46.36(2.65)$ & $44.47(3.11)$ \\
\hline Delayed free recall/16 & $10.93(2.66)$ & $10.82(3.00)$ & $11.03(2.33)$ & $11.21(2.06)$ & $10.71(3.06)$ & $10.90(2.55)$ & $10.50(3.60)$ & $11.21(2.04)$ & $11.20(2.14)$ \\
\hline Delayed total recall/16 & $15.61(0.85)$ & $15.48(1.06)$ & $15.74(0.57)$ & $15.79(0.49)$ & $15.47(1.03)$ & $15.75(0.55)$ & $15.17(1.34)$ & $15.71(0.61)$ & $15.87(0.35)$ \\
\hline TMT A, mean (SD) & $44.78(13.95)$ & $45.03(15.38)$ & $44.53(12.63)$ & $43.52(11.11)$ & $45.74(15.85)$ & $45.30(13.59)$ & $46.22(18.44)$ & $43.43(11.53)$ & $43.60(11.11)$ \\
\hline TMT B, mean (SD) & $114.36(36.35)$ & $116.03(41.27)$ & $112.74(31.48)$ & $108.56(35.06)$ & $118.97(37.20)$ & $119.22(29.85)$ & $118.69(45.11)$ & $103.77(32.63)$ & $113.00(37.84)$ \\
\hline Code test score, mean (SD) & $38.19(9.20)$ & $37.97(8.88)$ & $38.41(9.63)$ & $37.90(8.89)$ & $38.42(9.55)$ & $37.75(9.69)$ & $39.17(9.61)$ & $39.36(9.83)$ & $36.53(8.01)$ \\
\hline COWAT score, mean (SD) & $19.66(6.24)$ & $19.186 .59)$ & $20.12(5.94)$ & $20.34(6.34)$ & $19.13(6.20)$ & $19.65(6.39)$ & $18.56(6.10)$ & $20.79(5.38)$ & $19.93(7.28)$ \\
\hline CNT score, mean (SD) & $25.70(8.53)$ & $24.94(8.62)$ & $26.44(8.51)$ & $26.52(7.82)$ & $25.08(9.09)$ & $25.45(9.00)$ & $24.67(9.44)$ & $27.86(7.86)$ & $25.27(7.83)$ \\
\hline $\begin{array}{l}\text { ADCS-ADL PI } / 45 \text {; mean } \\
\text { (SD) }\end{array}$ & $40.00(4.72)$ & $39.27(5.43)$ & $40.73(3.83)$ & $40.45(4.54)$ & $39.65(4.89)$ & $40.00(4.16)$ & $39.28(5.65)$ & $41.71(3.22)$ & $39.27(5.34)$ \\
\hline GDS, mean (SD) & $2.33(1.85)$ & $2.67(1.67)$ & $2.00(1.98)$ & $2.41(2.01)$ & $2.26(1.75)$ & $1.90(1.74)$ & $2.67(1.71)$ & $2.14(2.35)$ & $2.67(1.68)$ \\
\hline AD-based SUVr, mean (SD) & $1.13(0.10)$ & $1.12(0.08)$ & $1.14(0.11)$ & $1.12(0.1)$ & $1.14(0.09)$ & $1.14(0.11)$ & $1.13(0.08)$ & $1.13(0.11)$ & $1.11(0.09)$ \\
\hline DHA ( $\mu \mathrm{g} / \mathrm{g} \mathrm{RBC})$, mean (SD) & $5.82(1.41)$ & $5.66(1.39)$ & $5.98(1.43)$ & $5.69(1.24)$ & $5.92(1.55)$ & $5.97(1.75)$ & $5.88(1.36)$ & $6.00(0.94)$ & $5.41(1.44)$ \\
\hline \multicolumn{10}{|c|}{ Medial temporal lobe atrophy, $N(\%)$} \\
\hline Stage 0 & $17(25.37)$ & $6(18.18)$ & $11(32.35)$ & $8(27.59)$ & $9(23.68)$ & $4(20)$ & $5(27.78)$ & $7(50)$ & $1(6.67)$ \\
\hline Stage 0.5 & $13(19.40)$ & $6(18.18)$ & $7(20.59)$ & $3(10.34)$ & $10(26.32)$ & $4(20)$ & $6(33.33)$ & $3(21.43)$ & $0(0)$ \\
\hline Stage 1 & $25(37.31)$ & $14(42.42)$ & $11(32.35)$ & $13(44.83)$ & $12(31.58)$ & $8(40)$ & $4(22.22)$ & $3(21.43)$ & $10(66.67)$ \\
\hline Stage 1.5 & $5(7.46)$ & $3(0.09)$ & $2(5.88)$ & $3(10.34)$ & $2(5.26)$ & $1(5)$ & $1(5.56)$ & $1(7.14)$ & $2(13.33)$ \\
\hline Stage 2 & $7(10.44)$ & $4(12.12)$ & $3(8.82)$ & $2(6.90)$ & $5(13.16)$ & $3(15)$ & $2(11.11)$ & $0(0)$ & $2(13.33)$ \\
\hline
\end{tabular}

Medial temporal lobe atrophy is the average of the left and right medial temporal lobes atrophy

Abbreviations: MMSE Mini-Mental State Examination, CDR Clinical Dementia Rating score, ADCS-ADL PI Alzheimer's Disease Cooperative Study-activities of daily living Prevention Instrument, TMT Trail Making Test, COWAT Controlled Oral Word Association Test, CNT Category Naming Test, GDS Geriatric Depression Scale, FCRST Free and Cued Selective Reminding Test, DHA docosahexaenoic acid, SUVr standardized uptake value relative 


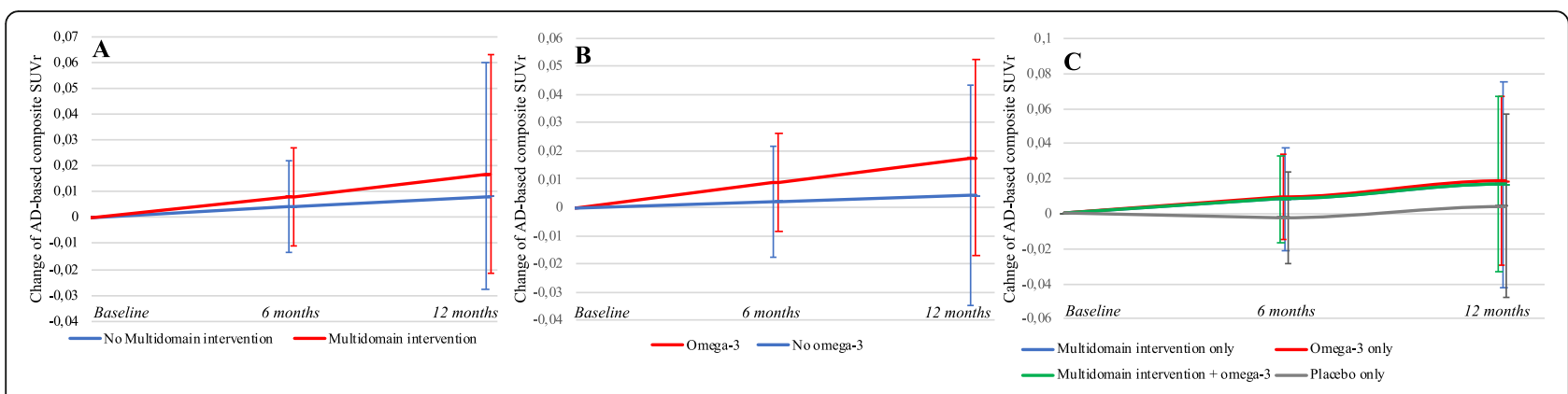

Fig. 2 Change of AD-based SUVr from baseline to 6- and 12-month visits in the MI group and No Ml group (a), in the Omega-3 group and No omega-3 group (b), and in the 3 active groups compared to control group (c). Abbreviations: MI, multidomain intervention; SUVr, standardized uptake value ratio

group (0.010 and $0.021, p=.603)$, in the Omega-3 only group (0.012 and $0.023, p=.524)$, and in the MI plus omega-3 (0.010 and 0.021, $p=.572)$ compared to the control group.

\section{Exploratory objectives assessed by voxel-wise approach}

At 12 months, there was no significant difference on metabolism change from baseline between the MI group and No MI group. At 6 months, the MI group increased metabolism compared to the No MI group in right hippocampus, right posterior cingulate, left posterior parahippocampal gyrus, and right insular cortex (uncorrected $p<.001, k>50$ voxels, Fig. 3). No difference on change of metabolism was found between Omega-3 group and No omega-3 group, either at 6 or 12 months. A difference on metabolism change was found in the right middle temporo-occipital gyrus when comparing the 4 groups (ANOVA), MI only group and omega-3

Table 2 Estimated mean difference in 6- and 12-month change from baseline on brain glucose metabolism for the active groups compared to the control group

\begin{tabular}{|c|c|c|c|c|c|c|}
\hline \multirow[t]{2}{*}{ Groups } & & \multirow[t]{2}{*}{$\mathbf{n}$} & \multirow{2}{*}{$\begin{array}{l}\text { Estimated mean } \\
\text { within-group change } \\
\text { from baseline }(95 \% \\
\mathrm{Cl})\end{array}$} & \multicolumn{3}{|c|}{$\begin{array}{l}\text { Estimated mean between-group differ- } \\
\text { ence in change from baseline }(95 \% \mathrm{Cl})\end{array}$} \\
\hline & & & & Vs control & $p$ & Adjusted $p^{*}$ \\
\hline \multicolumn{7}{|l|}{ Primary analysis } \\
\hline \multirow{2}{*}{$\begin{array}{l}\text { Effect of MI } \\
\text { At } 6 \text { months }\end{array}$} & MI plus placebo or omega-3 & 34 & $0.008(-0.011 ; 0.027)$ & $0.004(-0.022 ; 0.030)$ & 0.752 & 0.901 \\
\hline & No MI plus placebo or omega-3 & 33 & $0.004(-0.014 ; 0.022)$ & - & - & - \\
\hline \multicolumn{7}{|l|}{ Secondary analysis } \\
\hline \multirow[t]{2}{*}{ Effect of $\mathrm{Ml}$ at 12 months } & MI plus placebo or omega-3 & 34 & $0.016(-0.022 ; 0.055)$ & $0.008(-0.044 ; 0.061)$ & 0.752 & 0.901 \\
\hline & No MI plus placebo or omega-3 & 33 & $0.008(-0.027 ; 0.044)$ & - & - & - \\
\hline \multirow[t]{2}{*}{ Effect of omega- 3 at 6 months } & Omega-3 plus Ml or no Ml & 38 & $0.009(-0.009 ; 0.026)$ & $0.007(-0.019 ; 0.033)$ & 0.612 & 0.352 \\
\hline & No omega-3 plus $\mathrm{Ml}$ or no Ml & 29 & $0.002(-0.018 ; 0.022)$ & - & - & - \\
\hline \multirow[t]{2}{*}{ Effect of omega- 3 at 12 months } & Omega-3 plus Ml or no Ml & 38 & $0.018(-0.017 ; 0.052)$ & $0.013(-0.039 ; 0.066)$ & 0.612 & 0.352 \\
\hline & No omega-3 plus $\mathrm{Ml}$ or no Ml & 29 & $0.004(-0.035 ; 0.043)$ & - & - & - \\
\hline \multicolumn{7}{|l|}{ Exploratory analysis } \\
\hline \multirow{4}{*}{$\begin{array}{l}\text { Effect of MI, omega-3, and } \\
\text { combination of both at } 6 \text { months }\end{array}$} & Ml plus omega-3 & 20 & $0.008(-0.017 ; 0.033)$ & $0.010(-0.026 ; 0.047)$ & 0.572 & 0.552 \\
\hline & Omega-3 only & 18 & $0.009(-0.015 ; 0.033)$ & $0.012(-0.024 ; 0.047)$ & 0.524 & 0.236 \\
\hline & Ml only & 14 & $0.008(-0.021 ; 0.038)$ & $0.010(-0.029 ; 0.050)$ & 0.603 & 0.637 \\
\hline & Placebo & 15 & $-0.002(-0.028 ; 0.024)$ & - & - & - \\
\hline \multirow{4}{*}{$\begin{array}{l}\text { Effect of } \mathrm{Ml} \text {, omega- } 3 \text {, and } \\
\text { combination of both at } 12 \text { months }\end{array}$} & Ml plus omega-3 & 20 & $0.017(-0.034 ; 0.067)$ & $0.021(-0.052 ; 0.093)$ & 0.572 & 0.552 \\
\hline & Omega-3 only & 18 & $0.019(-0.030 ; 0.067)$ & $0.023(-0.048 ; 0.094)$ & 0.524 & 0.236 \\
\hline & Ml only & 14 & $0.017(-0.042 ; 0.075)$ & $0.021(-0.058 ; 0.100)$ & 0.603 & 0.637 \\
\hline & Placebo & 15 & $-0.004(-0.057 ; 0.048)$ & - & - & - \\
\hline
\end{tabular}

*Analysis adjusted for age, sex, level of education, APO $\varepsilon 4$ genotype, clinical dementia rating global score, and group intervention Abbreviation: MI multidomain intervention 

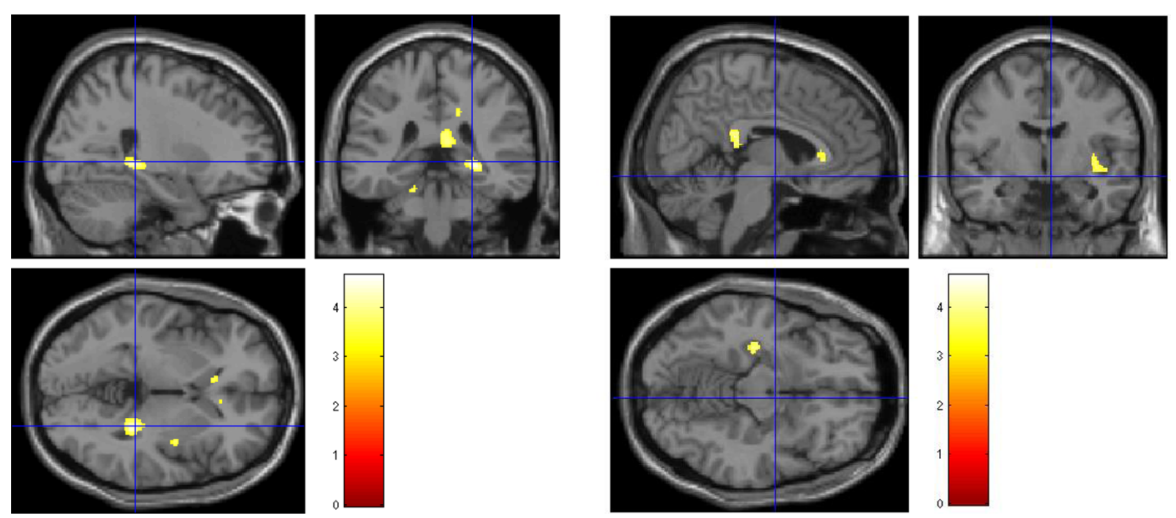

\begin{tabular}{|c|c|c|c|c|c|c|c|c|c|c|}
\hline \multicolumn{3}{|c|}{ Cluster-Level } & \multicolumn{4}{|c|}{ Peak-level } & \multicolumn{3}{|c|}{ Coordinates } & \multirow[b]{2}{*}{ Brain area } \\
\hline $\begin{array}{c}\text { Cluster } \\
\text { size }\end{array}$ & $\begin{array}{c}\mathrm{P} \\
\text { uncorrected }\end{array}$ & $\begin{array}{c}\mathrm{p} \\
\text { FWE }\end{array}$ & $\mathrm{P}$ uncorrected & $\begin{array}{c}\mathrm{p} \\
\mathrm{FWE}\end{array}$ & Z & $\mathrm{T}$ & $\mathrm{x}$ & $\mathrm{y}$ & $\mathrm{z}$ & \\
\hline 322 & 0.050 & 0.442 & $<.001$ & 0.276 & 4.27 & 4.64 & 29 & -36 & -3 & $\begin{array}{c}\text { Right } \\
\text { hippocampus }\end{array}$ \\
\hline 207 & 0.107 & 0.715 & $<.001$ & 0.768 & 3.84 & 4.10 & 6 & -36 & 20 & $\begin{array}{l}\text { Right posterior } \\
\text { cingulate }\end{array}$ \\
\hline 80 & 0.305 & 0.972 & $<.001$ & 0.907 & 3.68 & 3.92 & -32 & -21 & -12 & $\begin{array}{c}\text { Left posterior } \\
\text { parahippocampal } \\
\text { gyrus }\end{array}$ \\
\hline 75 & 0.321 & 0.977 & $<.001$ & 0.958 & 3.58 & 3.80 & 17 & -32 & 38 & $\begin{array}{l}\text { Right posterior } \\
\text { cingulate }\end{array}$ \\
\hline 150 & 0.165 & 0.856 & $<.001$ & 0.980 & 3.51 & 3.72 & 38 & -5 & 0 & $\begin{array}{l}\text { Right insular } \\
\text { cortex }\end{array}$ \\
\hline
\end{tabular}

Fig. 3 Results from the voxel-wise analysis comparing difference of metabolism from baseline to 6 months between the Ml group and No Ml group in MAPT-NI subjects

only group to control group (uncorrected $p<.001$ and $p$ FEW $<.05, k>50$ voxels, Table 3$)$ at 6 months.

\section{Effect of adherence and impact on cognitive performances}

The adherence (at least $75 \%$ of MI sessions or omega-3 supplementation) was $58.82 \%$ for the MI group and $78.94 \%$ for the Omega-3 group. Analyses of effect of MI, omega-3, and both according to adherence on metabolism were negative at 6- and 12-month visits (supplementary Table 1).

There was no significant difference between change on cognitive composite score from baseline to 6 and 12 months between the MI group and No MI group, between the Omega-3 group and No Omega group, and between the 3 active groups compared to the control group (supplementary Table 2). We only observed a marginal cognitive effect at 12 months in Omega-3 group with adherence $<75 \%(n=8)$ compared to control group ( $p=.002$, supplementary Table 3$)$.

\section{Discussion}

The hypothesis of a potential MI effect in early $A D$ stemmed from a cognitive benefit reported in positive amyloid subjects and APOE-4 carriers included respectively in MAPT-AV45 [3] and FINGER studies [4]. We expected that MI could affect positively metabolism in regions involved early in $\mathrm{AD}$. However, comparison of

Table 3 Results from the voxel-wise analysis comparing difference of metabolism from baseline to 6 months between the four groups, MI only group and control group, Omega-3 only group and control group

\begin{tabular}{|c|c|c|c|c|c|c|c|c|c|c|}
\hline \multicolumn{3}{|l|}{ Cluster-level } & \multicolumn{4}{|l|}{ Peak-level } & \multicolumn{3}{|c|}{ Coordinates } & \multirow[t]{2}{*}{ Brain area } \\
\hline Cluster size & $P$ uncorrected & $p$ FWE & $P$ uncorrected & $p$ FWE & $Z$ & $T$ & $x$ & $y$ & $z$ & \\
\hline \multicolumn{11}{|l|}{ ANOVA } \\
\hline 79 & 0.200 & 0.974 & $<.001$ & 0.626 & 4.06 & - & 68 & -41 & -6 & Right temporo-occipital gyrus \\
\hline \multicolumn{11}{|c|}{ Post hoc analysis } \\
\hline 61 & 0.084 & 0.003 & $<.001$ & 0.003 & 3.83 & 4.53 & 68 & -41 & -6 & Right temporo-occipital gyrus \\
\hline 79 & 0.125 & 0.004 & $<.001$ & $<.001$ & 4.33 & 5.12 & 69 & -39 & -8 & Right temporo-occipital gyrus \\
\hline
\end{tabular}

Maps were thresholded at $p<0.001$ (uncorrected) and $K>50$ voxels 
metabolic change from baseline to 6 and 12 months, between the MI group and the No MI group, showed no effect on the FDG-based AD biomarker. The results were similar in the analysis performed to test omega-3 supplementation and according adherence. The exploratory voxel-wise approach showed that the MI group had significant greater increase of metabolism compared to the No MI group at 6 months mainly in limbic lobe. No effect of MI was found at 12 months probably due to closer frequency of MI sessions at the beginning of MAPT-NI. An effect on metabolism of temporooccipital gyrus was showed in the MI only group. Temporo-occipital gyrus is affected in AD and involved on visuo-spatial process [24]. This increased metabolism is possibly due to MAPT memory program based mainly on mental imaging.

MI effect on limbic system metabolism at 6 months could suggest a disease-modifying effect on AD. Indeed, glucose metabolism is known to be associated with cognitive impairment severity [25], and limbic lobe is considered as a system involved early in AD [22]. In the literature, several studies suggested the effect of lifestyle on AD-based biomarkers. In dominant autosomal AD subjects, a high physical activity was associated with a lower AD-like pathology in cerebrospinal fluid [26]. In clinical trials, physical activity increased significantly hippocampal volume in older women with mild cognitive impairment (MCI) [27] and supplementation with B vitamins slowed the rate of brain atrophy in MCI subjects [28]. A program combining cognitive and physical training increased also parahippocampal cerebral blood flow [29].

\section{Strengths}

The strengths of MAPT-NI were the duration of intervention and objectives designed to assess the MI impact especially on FDG-based AD biomarker. We performed a ROI-based approach well described in the literature to assess the potential MI effect in early $\mathrm{AD}$ [22] and a complementary voxel-wise approach without anatomical hypothesis. Most trials that assessed effect of non-drug interventions on metabolism last less than 6 months [30]. The duration of MAPT-NI allowed to assess the MI effect by taking in account effect of potential associated disease progression on metabolism [30, 31]. Alexander et al. showed that brain metabolism is a sensitive marker of disease progression in AD over a 1 -year period [31]. In a sub-group MRI analysis of FINGER, no differences between active and control groups were found on the changes of regional volumes and cortical thickness, while the main study was positive on cognition [32]. Glucose metabolism is likely to be a more sensitive outcome involved earlier in the hypothetical AD model than atrophy biomarkers [33].

\section{Limitations}

The main limitation of MAPT-NI concerns the amyloid status, which was not known in MAPT-NI. Participants of MAPT-NI could not be recruited in MAPT-AV45 and reciprocally for safety reasons of radioprotection. Primary analysis could be negative potentially because only few positive amyloid subjects were included in MAPT-NI (from MAPT-AV45, we can expect approximately $30 \%$ of positive amyloid participants in MAPT-NI). In the absence of brain MRI scan at the 6-month visit, we did not perform FDG analysis in the subject MRI space but only in the MNI space which can potentially induce artifacts. Another limitation concerns the allocation of omega-3 supplementation in the MI group and No MI group. Indeed, the control group was the only group to show a decrease in glucose metabolism at 6 and 12 months while the combined intervention group (MI plus omega-3 group) did not increase brain metabolism compared to the MI only group. So, a study with larger groups of MI only and No MI without omega-3 supplementation (control group) could provide more promising results in favor of the MI only group.

\section{Conclusion}

MI had no significant effect on FDG-based AD biomarker. However, voxel-wise analysis showed an impact on limbic lobe at 6 months suggesting delay effect on AD progression. The lack of MI effect showed at 12 months suggests the necessity to maintain high frequency of MI sessions all along interventional program. These elements will need to be investigated further in non-demented subjects with positive amyloid status. The ongoing MIND-AD study (NCT03249688) which assess the effect of a MI and medical food on cognition in prodromal AD could provide an answer such as the Dutch study NL-ENIGMA (Effect of a specific Nutritional Intervention on cerebral Glucose Metabolism in early Alzheimer's disease) which explore effect of multinutrient combination in early $\mathrm{AD}$ on a FDG-based $\mathrm{AD}$ biomarker [34].

\section{Supplementary information}

Supplementary information accompanies this paper at https://doi.org/10. 1186/s13195-020-00683-6.

Additional file 1: Supplementary Fig. 1. Predefined cortical regions of interest included in primary outcome from Harvard-Oxford atlas. Supplementary Table 1. Estimated mean difference in 6- and 12-month

change from baseline on brain glucose metabolism for the intervention groups according to adherence compared to the "Control group » (No Ml and no omega-3 supplementation). Supplementary Table 2. 
Estimated mean difference in 6- and 12-month change from baseline on cognitive composite score for the intervention groups compared to the " Control group ». Supplementary Table 3. Estimated mean difference in 6- and 12-month change from baseline on cognitive composite score for the intervention groups according to adherence compared to the « Control group ».

\section{Abbreviations}

AD: Alzheimer disease; DHA: Docosahexaenoic acid; EPA: Eicosapentaenoic acid; FDG: Fluorodeoxyglucose; PET: Positron emission tomography; MI: Multidomain intervention; MAPT: Multidomain Alzheimer Prevention Trial; MRI: Magnetic resonance imaging; ROI: Region of interest; SUVr: Standardized uptake value ratio

\section{Acknowledgements}

We are indebted to the investigators from the University Hospital of Toulouse, Hôpital de Tarbes, Hôpital de Foix, Hôpital de Castres, the University Hospital of Limoges, the University Hospital of Bordeaux, Hôpital de Lavaur, the University Hospital of Montpellier, Hôpital de Montauban, and the University Hospital of Nice for their participation in this study. Members of the MAPT Study Group:

Bruno Vellas, Sophie Guyonnet, Isabelle Carrié, Lauréane Brigitte, Catherine Faisant, Françoise Lala, Julien Delrieu, Hélène Villars, Emeline Combrouze, Carole Badufle, Audrey Zueras, Sandrine Andrieu, Christelle Cantet, Christophe Morin, Gabor Abellan Van Kan, Charlotte Dupuy, Yves Rolland, Céline Caillaud, Pierre-Jean Ousset, Bertrand Fougère, Sherry Willis, Sylvie Belleville, Brigitte Gilbert, Francine Fontaine, Jean-François Dartigues, Isabelle Marcet, Fleur Delva, Alexandra Foubert, Sandrine Cerda, Marie-Noëlle Cuffi, Corinne Costes, Olivier Rouaud, Patrick Manckoundia, Valérie Quipourt, Sophie Marilier, Evelyne Franon, Lawrence Bories, Marie-Laure Pader, MarieFrance Basset, Bruno Lapoujade, Valérie Faure, Michael Li Yung Tong, Christine Malick-Loiseau, Evelyne Cazaban-Campistron, Françoise Desclaux, Colette Blatge, Thierry Dantoine, Cécile Laubarie-Mouret, Isabelle Saulnier, Jean-Pierre Clément, Marie-Agnès Picat, Laurence Bernard-Bourzeix, Stéphanie Willebois, lléana Désormais, Noëlle Cardinaud, Marc Bonnefoy, Pierre Livet, Pascale Rebaudet, Claire Gédéon, Catherine Burdet, Flavien Terracol, Alain Pesce, Stéphanie Roth, Sylvie Chaillou, Sandrine Louchart, Kristel Sudres, Nicolas Lebrun, Nadège Barro-Belaygues, Jacques Touchon, Karim Bennys, Audrey Gabelle, Aurélia Romano, Lynda Touati, Cécilia Marelli, Cécile Pays, Philippe Robert, Franck Le Duff, Claire Gervais, Sébastien Gonfrier, Yannick Gasnier, Serge Bordes, Danièle Begorre, Christian Carpuat, Khaled Khales, JeanFrançois Lefebvre, Samira Misbah El Idrissi, Pierre Skolil, Jean-Pierre Salles, Carole Dufouil, Stéphane Lehéricy, Marie Chupin, Jean-François Mangin, Ali Bouhayia, Michèle Allard, Frédéric Ricolfi, Dominique Dubois, Marie-Paule Boncoeur-Martel, François Cotton, Alain Bonafé, Stéphane Chanalet, Françoise Hugon, Fabrice Bonneville, Christophe Cognard, François Chollet, Pierre Payoux, Thierry Voisin, Sophie Peiffer, Anne Hitzel, Michèle Allard, Michel Zanca, Jacques Monteil, Jacques Darcourt, Laurent Molinier, Hélène Derumeaux, Nadège Costa, Christian Vincent, Bertrand Perret, Claire Vinel, Pascale Olivier-Abbal.

We thank Valérie Lauwers-Cances for the calculation of MAPT-NI sample size.

\section{Statistical analyses}

Christelle Cantet, MS (Toulouse University), performed the statistical analyses of this manuscript.

\section{Authors' contributions}

$J D, T V, L S A$, and SA conceived and designed the study. Data were analyzed and interpreted by CC, JD, SA, TV, PP, LSA, and BV. JD, LSA, and CC wrote the article, which was critically reviewed by all authors. The authors read and approved the final manuscript.

\section{Funding}

The MAPT study was supported by grants from the Gérontopôle of Toulouse, the French Ministry of Health (PHRC 2008, 2009), the Pierre Fabre Research Institute (manufacturer of the polyunsaturated fatty acid supplement), Exonhit Therapeutics, and Avid Radiopharmaceuticals. This study was supported by the University Hospital Center of Toulouse.

\section{Availability of data and materials}

The datasets generated and/or analyzed during the current study are not publicly available. However, clinical and FDG PET data can be shared by request via "Application for Access to the MAPT Database" (for further information contact of the Data Sharing Alzheimer group: Info.u1027dsa@inserm.fr).

\section{Ethics approval and consent to participate}

MAPT-NI study protocol was approved by the French Ethics Committee in Toulouse and AFSSAPS (national agency for the safety of drugs and health products) in February 2009. All MAPT participants gave written informed consent at baseline visit. Participants in MAPT-NI gave separate written consent for PET scans.

\section{Consent for publication}

Not applicable.

\section{Competing interests}

SA has received grants from Europe, Ipsen, and France Alzheimer; served as a consultant for Ipsen, Pierre Fabre, Lilly, Nestlé, Sanofi, and Servier; and received non-financial support from Biogen, Nutrition Santé, Pfizer, and Icon, and other forms of support from the AMPA Association. BV receives grants from Pierre Fabre, Avid, Exonhit, AbbVie, Lilly, Lundbeck, MSD, Otsuka, Regeneron, Sanofi, Roche, AstraZeneca, LPG Systems, Nestlé, and Alzheon and personal fees from Lilly, Lundbeck, MSD, Otsuka, Roche, Sanofi, Biogen, Nestlé, Transition Therapeutics, and Takeda. All the other authors declare no competing interests.

\section{Author details}

${ }^{1}$ Pôle gériatrie, Cité de la santé, Place Lange - TSA 60033, 31059 Toulouse Cedex 9, France. ${ }^{2}$ INSERM UMR 1027, Toulouse, France; University of Toulouse III, Toulouse, France. ${ }^{3}$ Gérontopôle, Department of Geriatrics, Toulouse (University Hospital) CHU, Purpan University Hospital, Toulouse, France. ${ }^{4}$ Toulouse Neurolmaging Center, University of Toulouse III, INSERM, UPS, Toulouse, France. ${ }^{5}$ Department of Nuclear Medicine, Toulouse CHU, Purpan University Hospital, Toulouse, France. ${ }^{6}$ Toulouse Neurolmaging Center, University of Toulouse, INSERM, UPS, Toulouse, France. ${ }^{7}$ Department of Epidemiology and Public Health, Toulouse CHU, Toulouse, France.

\section{Received: 23 June 2020 Accepted: 10 September 2020}

Published online: 19 October 2020

\section{References}

1. Vellas B, Carrie I, Gillette-Guyonnet S, Touchon J, Dantoine T, Dartigues JF, et al. Mapt study: a multidomain approach for preventing alzheimer's disease: design and baseline data. J Prev Alzheimers Dis. 2014;1(1):13-22.

2. Andrieu S, Guyonnet S, Coley N, Cantet C, Bonnefoy M, Bordes S, et al. Effect of long-term omega 3 polyunsaturated fatty acid supplementation with or without multidomain intervention on cognitive function in elderly adults with memory complaints (MAPT): a randomised, placebo-controlled trial. Lancet Neurol. 2017;16(5):377-89.

3. Delrieu J, Payoux P, Carrié I, Cantet C, Weiner M, Vellas B, Andrieu S. Multidomain intervention and/or omega-3 in nondemented elderly subjects according to amyloid status. Alzheimers Dement. 2019;15(11):1392-1401.

4. Solomon A, Turunen H, Ngandu T, Peltonen M, Levälahti E, Helisalmi S, et al. Effect of the apolipoprotein E genotype on cognitive change during a multidomain lifestyle intervention: a subgroup analysis of a randomized clinical trial. JAMA Neurol. 2018;75(4):462-70.

5. Jagust W, Reed B, Mungas D, Ellis W, Decarli C. What does fluorodeoxyglucose PET imaging add to a clinical diagnosis of dementia? Neurology. 2007;69(9):871-7.

6. Reiman EM, Alzheimer's Disease Biomarkers Working Group for the Alliance for Aging Research. Fluorodeoxyglucose positron emission tomography: emerging roles in the evaluation of putative Alzheimer's disease-modifying treatments. Neurobiol Aging. 2011;32(Suppl 1):S44-7.

7. Albert MS, DeKosky ST, Dickson D, Dubois B, Feldman HH, Fox NC, et al. The diagnosis of mild cognitive impairment due to Alzheimer's disease: recommendations from the National Institute on Aging-Alzheimer's Association workgroups on diagnostic guidelines for Alzheimer's disease. Alzheimers Dement J Alzheimers Assoc. 2011;7(3):270-9. 
8. Dubois B, Feldman HH, Jacova C, Cummings JL, Dekosky ST, BarbergerGateau P, et al. Revising the definition of Alzheimer's disease: a new lexicon. Lancet Neurol. 2010;9(11):1118-27.

9. Bailly M, Destrieux C, Hommet C, Mondon K, Cottier J-P, Beaufils E, et al. Precuneus and cingulate cortex atrophy and hypometabolism in patients with Alzheimer's disease and mild cognitive impairment: MRI and (18)F-FDG PET quantitative analysis using FreeSurfer. Biomed Res Int. 2015;2015: 583931.

10. Lorenzi M, Donohue M, Paternicò D, Scarpazza C, Ostrowitzki S, Blin O, et al. Enrichment through biomarkers in clinical trials of Alzheimer's drugs in patients with mild cognitive impairment. Neurobiol Aging. 2010;31(8):144351 1451.e1.

11. Yu P, Dean RA, Hall SD, Qi Y, Sethuraman G, Willis BA, et al. Enriching amnestic mild cognitive impairment populations for clinical trials: optimal combination of biomarkers to predict conversion to dementia. J Alzheimers Dis JAD. 2012;32(2):373-85.

12. Kivipelto M, Solomon A, Ahtiluoto S, Ngandu T, Lehtisalo J, Antikainen R, et al. The Finnish geriatric intervention study to prevent cognitive impairment and disability (FINGER): study design and progress. Alzheimers Dement J Alzheimers Assoc. 2013;9(6):657-65.

13. Richard E, Van den Heuvel E, Moll van Charante EP, Achthoven L, Vermeulen M, Bindels PJ, et al. Prevention of dementia by intensive vascular care (PreDIVA): a cluster-randomized trial in progress. Alzheimer Dis Assoc Disord. 2009;23(3):198-204.

14. Scheltens $P$, Leys $D$, Barkhof $F$, Huglo D, Weinstein HC, Vermersch $P$, et al. Atrophy of medial temporal lobes on MRI in "probable" Alzheimer's disease and normal ageing: diagnostic value and neuropsychological correlates. J Neurol Neurosurg Psychiatry. 1992;55(10):967-72.

15. Grober E, Buschke H, Crystal H, Bang S, Dresner R. Screening for dementia by memory testing. Neurol. 1988;38(6):900-3.

16. Cardebat D, Doyon B, Puel M, Goulet $P$, Joanette $Y$. Formal and semantic lexical evocation in normal subjects. Performance and dynamics of production as a function of sex, age and educational level. Acta Neurol Belg. 1990;90(4):207-17.

17. Wechsler D. Wechsler adult intelligence scale-revised, Psychological Corp In 1981.

18. Reitan R. Validity of the Trail Making Test as an indicator of brain damage. Percept Mot Skills. 1958:271-6.

19. Folstein MF, Folstein SE, McHugh PR. "Mini-mental state". A practical method for grading the cognitive state of patients for the clinician. J Psychiatr Res 1975;12(3):189-198.

20. Hughes $C P$, Berg L, Danziger WL, Coben LA, Martin RL. A new clinical scale for the staging of dementia. Br J Psychiatry J Ment Sci. 1982;140:566-72.

21. Chhetri JK, de Souto BP, Cantet C, Cesari M, Coley N, Andrieu S, et al. Trajectory of the MAPT-PACC-preclinical Alzheimer cognitive composite in the Placebo Group of a Randomized Control Trial: results from the MAPT Study: lessons for further trials. J Prev Alzheimers Dis. 2018;5(1):31-5.

22. Landau SM, Harvey D, Madison CM, Koeppe RA, Reiman EM, Foster NL, et al. Associations between cognitive, functional, and FDG-PET measures of decline in AD and MCl. Neurobiol Aging. 2011;32(7):1207-18.

23. de Leon MJ, Convit A, Wolf OT, Tarshish CY, DeSanti S, Rusinek H, et al. Prediction of cognitive decline in normal elderly subjects with 2[(18)F]fluoro-2-deoxy-D-glucose/poitron-emission tomography (FDG/PET). Proc Natl Acad Sci U S A. 2001;98(19):10966-71.

24. Ding B, Ling H, Zhang $Y$, Huang J, Zhang H, Wang T, et al. Pattern of cerebral hyperperfusion in Alzheimer's disease and amnestic mild cognitive impairment using voxel-based analysis of 3D arterial spin-labeling imaging: initial experience. Clin Interv Aging. 2014;9:493-500.

25. Jack CR, Bennett DA, Blennow K, Carrillo MC, Dunn B, Haeberlein SB, et al. NIA-AA research framework: toward a biological definition of Alzheimer's disease. Alzheimers Dement J Alzheimers Assoc. 2018;14(4):535-62.

26. Müller S, Preische $\mathrm{O}$, Sohrabi HR, Gräber $\mathrm{S}$, Jucker M, Ringman JM, et al. Relationship between physical activity, cognition, and Alzheimer pathology in autosomal dominant Alzheimer's disease. Alzheimers Dement J Alzheimers Assoc. 2018;14(11):1427-37.

27. ten Brinke LF, Bolandzadeh N, Nagamatsu LS, Hsu CL, Davis JC, Miran-Khan $\mathrm{K}$, et al. Aerobic exercise increases hippocampal volume in older women with probable mild cognitive impairment: a 6-month randomised controlled trial. Br J Sports Med. 2015;49(4):248-54.

28. Smith AD, Smith SM, de Jager CA, Whitbread P, Johnston C, Agacinski G, et al. Homocysteine-lowering by $B$ vitamins slows the rate of accelerated brain atrophy in mild cognitive impairment: a randomized controlled trial. PloS One. 2010;5(9):e12244.

29. Train the Brain Consortium. Randomized trial on the effects of a combined physical/cognitive training in aged MCl subjects: the Train the Brain study. Sci Rep. 2017;7:39471.

30. Herholz K. Use of FDG PET as an imaging biomarker in clinical trials of Alzheimer's disease. Biomark Med. 2012;6(4):431-9.

31. Alexander GE, Chen K, Pietrini P, Rapoport SI, Reiman EM. Longitudinal PET evaluation of cerebral metabolic decline in dementia: a potential outcome measure in Alzheimer's disease treatment studies. Am J Psychiatry. 2002; 159(5):738-45.

32. Stephen R, Liu Y, Ngandu T, Antikainen R, Hulkkonen J, Koikkalainen J, et al. Brain volumes and cortical thickness on MRI in the Finnish Geriatric Intervention Study to Prevent Cognitive Impairment and Disability (FINGER). Alzheimers Res Ther. 2019;11(1):53.

33. Jack CR, Knopman DS, Jagust WJ, Shaw LM, Aisen PS, Weiner MW, et al. Hypothetical model of dynamic biomarkers of the Alzheimer's pathological cascade. Lancet Neurol. 2010;9(1):119-28.

34. Scheltens NME, Kuyper IS, Boellaard R, Barkhof F, Teunissen CE, Broersen LM, et al. Design of the NL-ENIGMA study: exploring the effect of Souvenaid on cerebral glucose metabolism in early Alzheimer's disease. Alzheimers Dement N Y N. 2016;2(4):233-40.

\section{Publisher's Note}

Springer Nature remains neutral with regard to jurisdictional claims in published maps and institutional affiliations.

\section{Ready to submit your research? Choose BMC and benefit from:}

- fast, convenient online submission

- thorough peer review by experienced researchers in your field

- rapid publication on acceptance

- support for research data, including large and complex data types

- gold Open Access which fosters wider collaboration and increased citations

- maximum visibility for your research: over $100 \mathrm{M}$ website views per year

At BMC, research is always in progress.

Learn more biomedcentral.com/submissions 